\title{
Expression of HOTAIR and MEG3 are negatively associated with H. pylori positive status in gastric cancer patients
}

\author{
Farnaz Amini ${ }^{1}$, Mohammad Khalaj-Kondori ${ }^{1}$, Amin Moqadami ${ }^{1}$ and Ali Rajabi ${ }^{1}$ \\ ${ }^{1}$ Department of Animal Biology, Faculty of Natural Sciences, University of Tabriz, Tabriz, Iran \\ Correspondence to: Mohammad Khalaj-Kondori, email: Khalaj@tabrizu.ac.ir \\ Keywords: MEG3; HOTAIR; gastric cancer; biomarker; InCRNA \\ Received: October 26, $2021 \quad$ Accepted: February 02, $2022 \quad$ Published: February 10, 2022
}

Copyright: (ㅇ 2022 Amini et al. This is an open access article distributed under the terms of the Creative Commons Attribution License (CC BY 3.0), which permits unrestricted use, distribution, and reproduction in any medium, provided the original author and source are credited.

\section{ABSTRACT}

Background: Chronic infection with Helicobacter pylori is one of the main causes of gastric cancer (GC). Besides, IncRNAs play crucial roles in cancer pathobiology including GC. Here we aimed to investigate the expression of MEG3 and HOTAIR in gastric cancer tissues and evaluate their association with the $H$. pylori status.

Materials and Methods: One hundred samples were obtained. Total RNA was extracted, CDNA was synthesized and expression of MEG3 and HOTAIR was assessed using qRT-PCR. Association of their expression with $H$. pylori status and other clinicopathological characteristics were investigated. Furthermore, sensitivity and specificity of the MEG3 and HOTAIR expression levels for discrimination of the tumor and non-tumor samples were evaluated by Receiver operating characteristic (ROC) curve analysis.

Results: We observed upregulation of HOTAIR but downregulation of MEG3 in tumor compared to the non-tumor tissues. We also found a significant negative association between their expression levels and $\boldsymbol{H}$. pylori positive status. However, only the expression level of HOTAIR was significantly associated with the size and stage of the tumor $(P<0.05)$. The ROC curve analysis revealed that the expression levels of MEG3 and HOTAIR might discriminate GC tumor and non-tumor tissues.

Conclusions: In conclusion, this study revealed a negative association between $H$. pylori infection and expression of MEG3 and HOTAIR. The results suggested that the expression level of these IncRNAs might be considered as potential biomarkers for GC.

\section{INTRODUCTION}

According to the GLOBOCAN project of the International Agency for Research on Cancer (IARC), approximately $5.7 \%$ of all diagnosed cancer cases belonged to gastric cancer (GC), with 782,685 related deaths in 2018 worldwide [1]. Following the lung and colorectal cancer-related deaths, GC was responsible for $8.2 \%$ of all cancer-related deaths and placed in the third most common malignancies in 2018 [1]. It was reported that the incidence of GC was higher in adults aged $<50$ years, and two- to three-fold higher for men than women [2]. Four subgroups of GC have been identified including chromosomally unstable tumors (50\%), Epstein-Barr virus-positive (9\%), genomically stable tumors $(20 \%)$, and microsatellite unstable tumors $(22 \%)$ [3]. Furthermore, association between Helicobacter pylori (H. pylori) infection and gastric cancer has also been documented $[4,5]$. It was reported that treatment of H. pylori infection in patients with early gastric cancer reduced the risk of developing gastric cancer by $50 \%$ [6]. A meta-analysis of six randomized trials revealed that treatment of $\mathrm{H}$. pylori infection in general population may prevent developing of gastric cancer by a cancer relative risk of 0.66 [7].

Long noncoding RNAs (lncRNAs) functionally involved in gene expression regulation at chromatin, transcriptional, translational, and post-translational modification levels in cancer progression [4, 5]. Recently, dysregulation of various lncRNAs, such as MIR100HG, BANCR, H19, CASC15, MALAT1, TUSC7, MEG3, and HOTAIR in apoptosis, cell proliferation, migration, metastasis, invasion, and tumorigenicity of GC has been reported by different studies [6-11]. 
Maternally expressed gene 3 (MEG3) lncRNA is characterized as a tumor suppressor gene and its downregulation has been shown in many cancers, including GC [12]. It has been reported that the expression of MEG3 was lower in GC tissues compared to adjacent normal tissues [10]. This downregulation is mediated by hypermethylation of the MEG3 promoter region which, in turn, provokes GC progression [13, 14]. MEG3 not only regulates the p53 expression but also affects EMT, invasion, and migration of GC via sponging miRNAs including miR-181 and miR-21 by acting as a competing endogenous RNA (ceRNA) [15-17].

LncRNA HOTAIR (Hox transcript antisense intergenic RNA), located on chromosome 12q13.13, was first described by Rinn et al. in 2007 [18]. The HOTAIR exerts its function by downregulating the expression of HOXD locus and some other genes. HOTAIR affects expression of multiple genes, especially those involved in the invasion and metastasis [18]. Emerging studies have identified that HOTAIR exerts its function through sponging miRNAs, including miR-34a, miR-331-3p, and miR-217, suggesting its correlation with poor diagnosis of GC [19-21]. Although HOTAIR acts as a tumor oncogene and its overexpression has been indicated in the primary and metastatic GC compared to adjacent non-tumor tissues, still it is regarded as an independent diagnosis biomarker to predict the risk $\mathrm{GC}$ and mortality rates in patients with GC [22].

Here we assessed the expression of lncRNAs MEG3 and HOTAIR in GC and analyzed their association with the H. pylori status and other clinicopathological characteristics of the patients. Moreover, their biomarker potency was evaluated by the Receiver operating characteristic (ROC) curve analysis.

\section{RESULTS}

\section{Patients}

A total of $100 \mathrm{GC}$ patients were included in the study. Table 1 represents the clinicopathological features of the patients. $68 \%$ of the patients were female but $32 \%$ male. Regarding age distribution, fifty patients were $\leq 50$ years old and fifty were $>50$ years old. The majority of patients were positive for H.pylori (55\%).

\section{Expression of MEG3 and HOTAIR was negatively correlated in GC tissues}

Expression of MEG3 and HOTAIR IncRNAs was quantified by qRT-PCR and compared between tumor and non-tumor tissues. We observed a significant decrease in the MEG3 expression level in tumor tissues compared with the paired non-tumor tissues $(P$-value $<0.0001)$ (Figure 1A). On the other hand, HOTAIR expression showed a significant increase in tumor tissues compared with the paired non- tumor ones ( $P$-value $<0.0001)$ (Figure 1B). Finally, we investigated the correlation of MEG3 and HOTAIR expression levels (Figure 1C). The results demonstrated a significant negative correlation (Spearman $\mathrm{r}=-0.409$; $P<0.0001)$ indicating an inverse correlation between the expressions of these genes (Figure 1C).

\section{Expression of MEG3 and HOTAIR were negatively associated with the H-pylori positive status in GC patients}

Associations of MEG3 and HOTAIR expression with the clinicopathological characteristics of the patients were also investigated and represented in Table 2 . Results showed that MEG3 $(P=0.013)$ and HOTAIR $(P=0.001)$ expression levels were significantly higher in the $H$. pylori negative patients compared with the $H$. pylori positive group, indicating a negative association with the $H$. Pylori infection (Table 2). However, the expression of MEG3 did not show any significant association with the other clinicopathological features. But, we found significant associations between the expression of HOTAIR with the size $(P=0.017)$ and stage $(P=0.031)$ of the tumor. Other patients' clinicopathological characteristics such as age, gender, and metastasis status did not show any association with the expression level of HOTAIR (Table 2).

\section{MEG3 and HOTAIR expression levels may discriminate GC tumor and non-tumor samples}

To reveal biomarker potency of MEG3 and HOTAIR expression for GC, ROC curve analysis was used (Figure 2). The area under the curve (AUC) of MEG3 was 0.8736 and the AUC of the HOTAIR was 0.8711. Using the cut-off value of 0.0014 , the sensitivity and specificity of MEG3 were $79 \%$ and $86 \%$, respectively. On the other hand, using the cut-off value of 0.0024 , the sensitivity and specificity of HOTAIR were $84 \%$ and $74 \%$, respectively (Table 3). These results indicated that both MEG3 and HOTAIR expression levels may effectively discriminate GC tumor from non-tumor samples.

\section{DISCUSSION}

In the current study, a significantly lower expression of MEG3 was observed in GC tissues as compared to adjacent non-tumor tissues which is in consistent with the tumor suppressor function of this lncRNA. On the other hand, consistent with the oncogenic function of HOTAIR, we observed a significantly higher expression of HOTAIR in GC tissues as compared to adjacent non-tumor tissues. Also, the association of the expressions level of HOTAIR and MEG3 was investigated with regards to $H$. pylori status. The results clearly showed a negative association of the expression levels of the studied lncRNAs and $H$. pylori infection. Furthermore, the diagnostic potential of 


\begin{tabular}{lc}
\hline Clinical characteristics & Number \\
\hline Age & 50 \\
$\leq 50$ & 50 \\
$>50$ & \\
Gender & 37 \\
Male & 63 \\
Female & \\
Metastasis & 43 \\
Yes & 57 \\
No & \\
Size & 42 \\
$\geq 5$ cm & 58 \\
$<5$ cm & \\
Stage & 50 \\
I, II & 50 \\
III, IV & \\
H. Pylori & 55 \\
Positive & 55 \\
Negative & \\
\hline
\end{tabular}
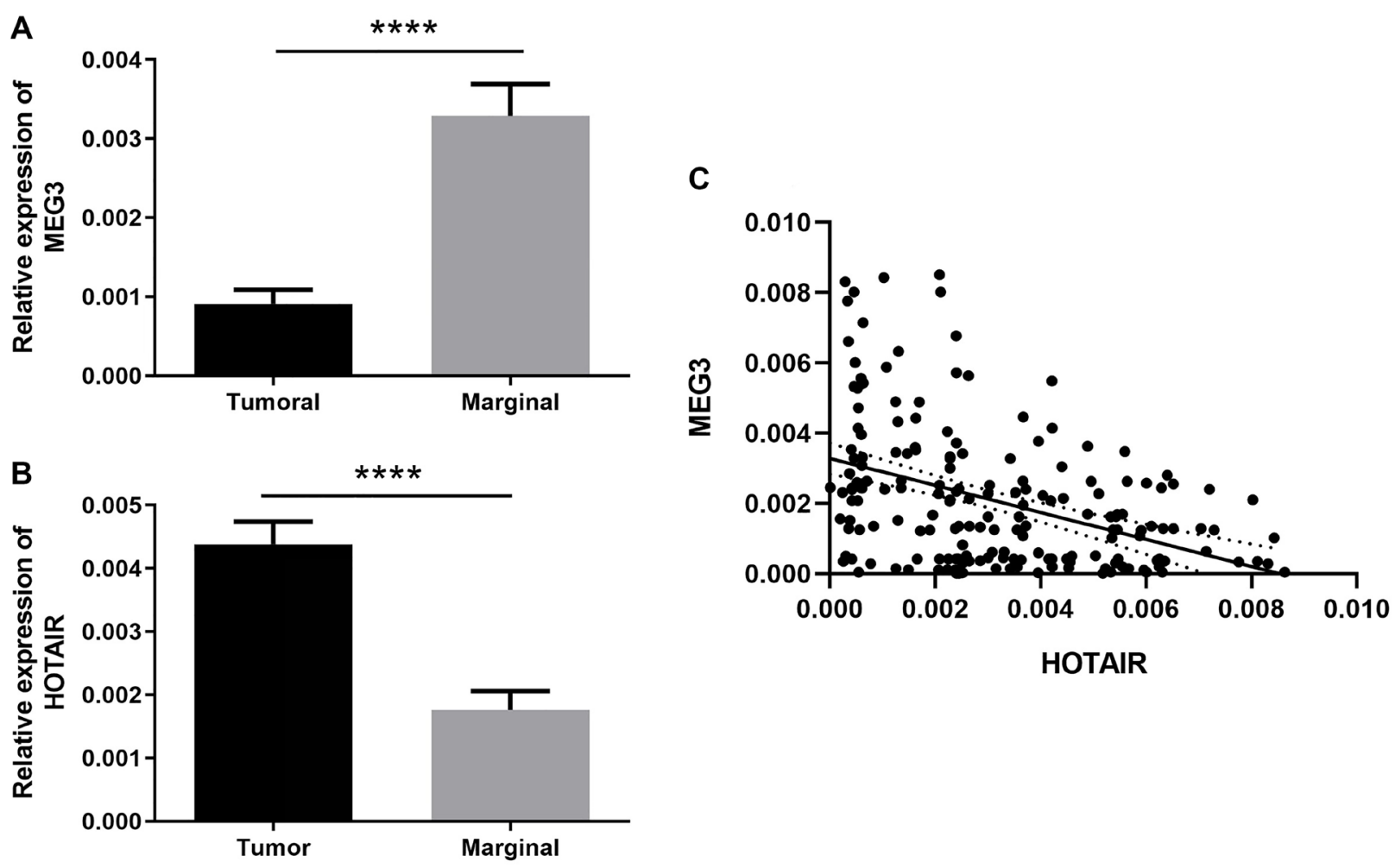

Figure 1: Differences in the expression level of IncRNAs in tumors as compared to the marginal non-tumor tissues at mRNA level represented by bar plot. (A) The relative expression of MEG3 in tumor tissues was significantly lower than adjacent non-tumor tissues. (B) The relative expression of HOTAIR in tumor tissues was significantly higher than marginal non-tumor tissues. ${ }^{* * * *}$ represents $P<0.0001)$. (C) The correlation between MEG3 and HOTAIR expression level by dot plot. Spearman correlation coefficient is $\mathrm{r}=-0.409(95 \% \mathrm{CI}=-0.5211$ to -0.2824$)$ which indicates an inverse correlation. 
Table 2: Association between MEG3 and HOTAIR expression with the clinicopathological features in patients with $\mathbf{G C}$

\begin{tabular}{|c|c|c|c|c|c|}
\hline $\begin{array}{l}\text { Clinical } \\
\text { parameter }\end{array}$ & No. of cases & $\begin{array}{l}\text { Expression means of } \\
\text { MEG3 (fold change) }\end{array}$ & $P$-value & $\begin{array}{l}\text { Expression means of } \\
\text { HOTAIR (fold change) }\end{array}$ & $P$-value \\
\hline Age & & & 0.727 & & 0.206 \\
\hline$\leq 50$ & 50 & 22.15 & & 10.07 & \\
\hline$>50$ & 50 & 17.49 & & 6.04 & \\
\hline Gender & & & 0.752 & & 0.400 \\
\hline Male & 37 & 33.92 & & 12.13 & \\
\hline Female & 63 & 10.02 & & 5.22 & \\
\hline Metastasis & & & 0.688 & & 0.641 \\
\hline Yes & 43 & 15.09 & & 4.94 & \\
\hline No & 57 & 23.39 & & 10.40 & \\
\hline Size & & & 0.331 & & 0.017 \\
\hline$\geq 5 \mathrm{~cm}$ & 42 & 21.64 & & 8.56 & \\
\hline$<5 \mathrm{~cm}$ & 58 & 18.21 & & 7.60 & \\
\hline Stage & & & 0.593 & & 0.031 \\
\hline I, II & 50 & 17.21 & & 9.07 & \\
\hline III, IV & 50 & 22.65 & & 6.96 & \\
\hline H. Pylori & & & 0.013 & & 0.001 \\
\hline Positive & 55 & 17.68 & & 6.66 & \\
\hline Negative & 45 & 24.58 & & 11.16 & \\
\hline
\end{tabular}

Table 3: LncRNAs expression status as diagnostic biomarkers for GC in terms of sensitivity and specificity

\begin{tabular}{lccc}
\hline Long non-coding RNA & Cutoff value & Sensitivity (\%) & Specificity (\%) \\
\hline MEG3 & 0.0014 & 79 & 86 \\
HOTAIR & 0.0024 & 84 & 74 \\
\hline
\end{tabular}

the two lncRNAs was investigated by ROC curve analysis. The results showed that MEG3 and HOTAIR expression levels could discriminate tumor from non-tumor tissues with specificities $86 \%$ and $74 \%$, and sensitivities $79 \%$ and $84 \%$ respectively. Considering the AUC values 0.8736 and 0.8711 obtained for MEG3 and HOTAIR respectively, it might be concluded that both MEG3 and HOTAIR are potential biomarkers for $\mathrm{GC}$ development.

During the past years, MEG3 and HOTAIR expression has been investigated in various cancer types; however, the precise molecular mechanism by which these lncRNAs promote tumorigenesis remains unclear. Regarding the role of MEG3 as a tumor suppressor gene, a study conducted by Guo et al. demonstrated the downregulation of MEG3 in endometrial carcinoma [23]. MEG3 positively was correlated with p53 expression and a decrease in MEG3 expression level was resulted in downregulation of p53 and apoptosis suppression $[10,24]$. Besides, MEG3 functions through repressing notch 1 and PI3K/m-TOR signaling pathways [25]. Wei et al. reported downregulation of MEG3 in GC tissues compared to adjacent normal tissues and demonstrated a negative correlation between MEG3 expression and the tumor size and TNM stage. Based on these findings, they proposed MEG3 as a potential diagnostic biomarker for GC [10]. The same suggestion was concluded by Sun et al. [13]. Another study evaluated the MEG3 expression and showed that its promoter region hypermethylation leads to downregulation of MEG3 in GC tissues compared to normal tissues [14]. Besides, they demonstrated the negative expression of MEG3 with TNM stage and tumor size. Furthermore, they suggested that MEG3 regulates the apoptosis of GC by targeting of miR-21 [14]. Another study showed downregulation of MEG3 in GC tissues by sponging miR-181 and its contribution to the GC invasion [15]. All these reports are in line with our findings.

It has been reported that HOTAIR contributes to epigenome regulation and chromatin remodeling [24]. Polycomb proteins act as an inhibitor of transcription of several genes, which contribute to cell differentiation $[26,27]$. These proteins exist in polycomb repressive complex (PRC) 1 and PRC2. PRC2 regulates the H3K27 
methylation and involves in gene silencing [28]. In fact, HOTAIR binds and guides the PRC2, where PRC2 exerts the function of gene expression silencing. Furthermore, p21WAF1/CIP1 is a gene that is repressed by HOTAIR, resulting in dysfunction of p53-induced growth arrest and apoptosis [29]. Xiao et al. suggested that HOTAIR regulated proliferation and metastasis of GC through SDF1/CXCR4 and RhoA signaling pathways by sponging miR-126 [22]. They observed overexpression of HOTAIR in GC and demonstrated that HOTAIR reduces the miR126 expression, leading to GC invasiveness [22]. HOTAIR was associated with clinicopathological features of GC patients, including tumor size and tumor stage [20, 30], suggesting its potential as a diagnostic biomarker in GC [30]. Our results are in consistent with these reports.

Recently, a research group evaluating the expression of HOTAIR in 49 GC tissues and their adjacent non-tumor tissues has reported that expression level of HOTAIR is not related to the proportion of
H. pylori infection $(P=0.30)$ [31]. In this work they showed that HOTAIR interacts with miR-148b and DNA methyltransferase 1 (DNMT1). The DNMT1 promotes methylation of a well-known tumor suppressor gene, Protocadherin 10 (PCDH10), which contributes to the progression of GC [31]. Similarly, a previous study investigating the relation between mir-141 and MEG3 in GC tissues in comparison with adjacent nontumor tissues has demonstrated no significant changes in MEG3 expression in $H$. pylori positive samples compared to $H$. pylori negative samples $(P>0.05)$ [32]. In a study conducted in 2019, a study group has assessed the association of HOTAIR expression level and H. pylori infection [33]. Opposite to our finding, the results of this study have indicated a significant higher HOTAIR expression in $H$. pylori positive patients (20.8\%) compared to $H$. pylori negative patients $(2.9 \%)$ with $P$-value of 0.017 [33]. This discrepancy might be due to differences in the populations genetic background
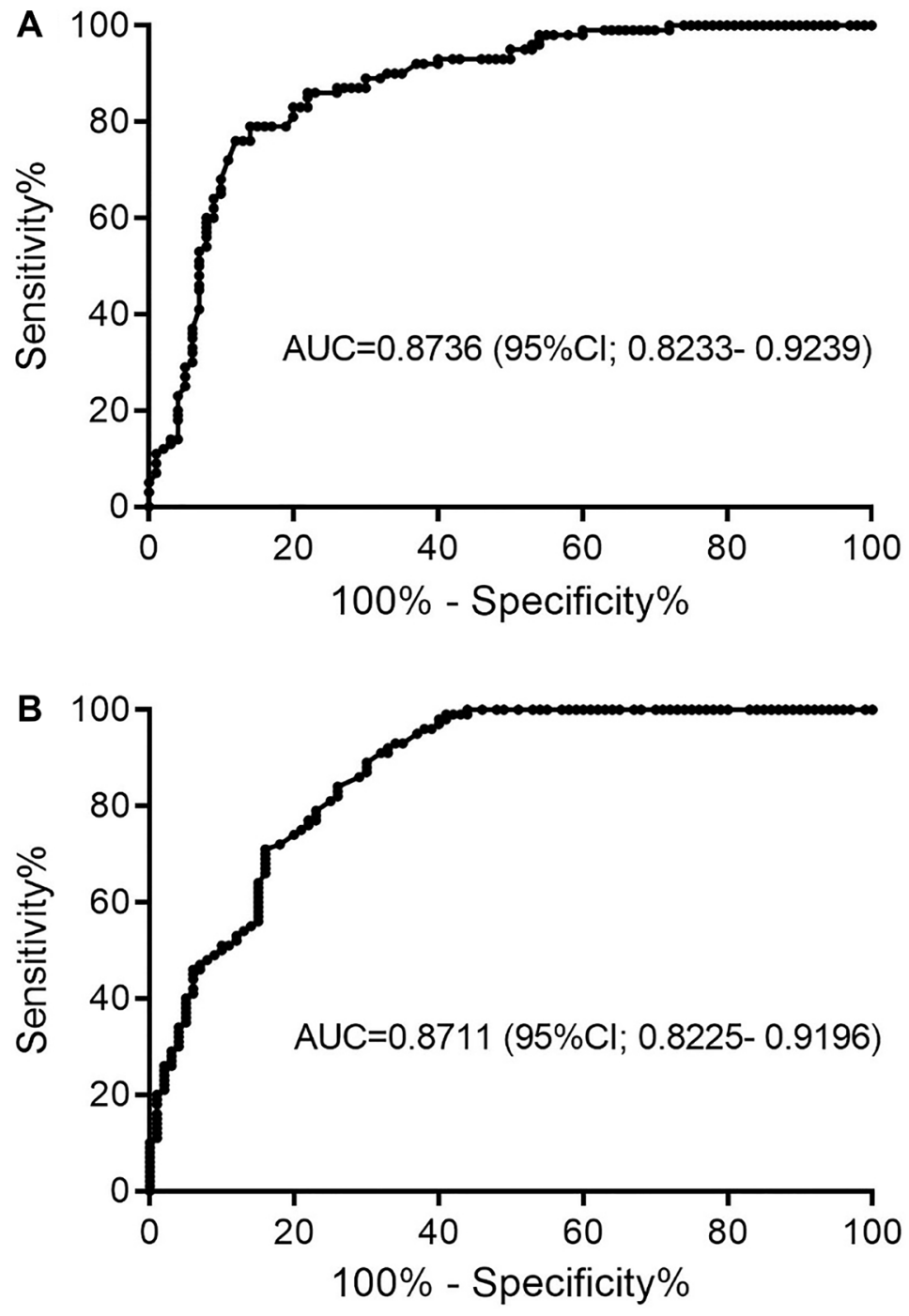

Figure 2: The ROC curve analysis indicating biomarker potency of (A) MEG3 and (B) HOTAIR. Abbreviation: AUC; Area under the cuve. 
and reflects the effect of complex interactions between lncRNAs, miRNAs and mRNAs governing cancer cell behavior [34].

We also investigated the correlation of HOTAIR and MEG3 expression GC samples. Our results revealed a negative correlation between HOTAIR and MEG3 expressions, meaning that a higher expression level HOTAIR might lead to the downregulation of MEG3. This finding is in line with other reports and confirms the functional link of HOTAIR and MEG3 in GC pathology. As reported by Bian et al., upregulation of HOTAIR occupies the PRC2 and drastically increases the $\mathrm{H} 3 \mathrm{~K} 27 \mathrm{me} 3$ at the promoter region of MEG3, leading to epigenetically silencing of MEG3 in the hepatic stellate cells [35]. Finally, MEG3 functions through p53/MDM2 signaling pathways and downregulates p53, leading to GC development [35].

\section{MATERIALS AND METHODS}

\section{Patients and samples}

One hundred gastric tumor and adjacent nontumor tissues were obtained from Noor-E-Nejat hospital, Tabriz, Iran. Written informed consent was acquired from all participants and the study was approved by the Medical Ethical Committee of the University of Tabriz (IR. TABRIZU. REC. 1398.015). An expert pathologist assessed, characterized, and validated the histopathology features of the tissue's samples.

\section{RNA isolation, cDNA synthesis and qRT-PCR}

Total RNA was extracted from tumor and non-tumor tissues using TRIZOL reagent (Invitrogen, Massachusetts, USA) according to the company's protocol. DNaseI (GeneAll, Seoul, Korea) was utilized to eliminate any DNA contamination. NanoDrop (Thermo Fisher scientific Nanodrop 2000, CA, USA) was used to assess the quantity and quality of RNA samples followed by $2 \%(\mathrm{v} / \mathrm{w})$ agarose gel electrophoresis.

The PrimeScript ${ }^{\mathrm{TM}} 1$ st Strand cDNA Synthesis Kit (TaKaRa, Kusatsu, Japan) was used to synthesis the cDNA according to the manufacturer's protocol. Approximately $100 \mathrm{ng}$ of cDNA was used for amplification of lncRNAs MEG3 and HOTAIR using LightCycler ${ }^{\circledR}$ 96 Real-Time PCR (Roche Molecular Systems, Inc., Pleasanton, CA, USA) with SYBR Green Master Mix (2x) (Amplicon, Odense, Denmark). The primer pairs utilized for amplification of MEG3, HOTAIR, and $\beta$-actin (as internal control) were as followings: MEG3; F: 5'-CTGCCCATCTACACCTCACG-3', R: 5'-CT CTCCGCCGTCTGCGCTAGGGGCT-3', HOTAIR; F: 5'GGCAGCACAGAGCAACTCTA-3', R: 5'-GAGTGCA AAGTCCCGTTTG-3', and $\beta$-actin; F: 5'-AGAGCT ACGAGCTGCCTGAC-3'， R: 5'-AGCACTGTCTTG
GCGTACAG-3'. The relative expressions were calculated by the formula $2^{-\Delta \mathrm{Ct}}$. All reactions were run in duplicate format.

\section{ROC curve analysis}

The potential of the MEG3 and HOTAIR as diagnostic biomarkers in GC was assessed by the receiver operating characteristic curve analysis. The ROC curve plots the true positive rate (TPR) against the false positive rate (FPR) at various threshold settings. Thus, the sensitivity and specificity of the markers can be determined at specific threshold values. Also, the area under the curve (AUC) was identified to describe the variation of the sensitivity and specificity of the lncRNAs.

\section{Statistical analysis}

The expression of MEG3 and HOTAIR in tumors and non-tumor samples were compared with Mann-Whitney statistical test. The association between MEG3 and HOTAIR expression levels and the clinicopathological features was investigated using student's $t$-test and one-way ANOVA. $T$-test was employed in the case of normal distribution, otherwise, the Mann-Whitney test was used. The correlation between MEG3 and HOTAIR expression levels was analyzed by Spearman correlation test. All statistical analyses were performed by GraphPad Prism v.8.4.3 and $P$-values $<0.05$ were considered as significant.

\section{CONCLUSIONS}

The expression of MEG3 and HOTAIR was negatively associated with the $H$. pylori positive status. MEG3 was downregulated but HOTAIR was upregulated in the GC tissues. The expression of HOTAIR was associated with the size and stage of tumor. Furthermore, MEG3 and HOTAIR expression levels might be considered as potential diagnostic biomarkers for GC.

\section{Author contributions}

Conceptualization and study design, Mohammad Khalaj-Kondori, Implementation of the experiments; Farnaz Amini and Ali Rajabi, Data analysis and interpretation; Farnaz Amini and Amin Moqadami, Manuscript draft preparation; Farnaz Amini, Editing; Amin Moqadami and Ali Rajabi, Supervision; Mohammad Khalaj-Kondori.

\section{CONFLICTS OF INTEREST}

Authors have no conflicts of interest to declare. 


\section{REFERENCES}

1. Bray F, Ferlay J, Soerjomataram I, Siegel RL, Torre LA, Jemal A. Global cancer statistics 2018: GLOBOCAN estimates of incidence and mortality worldwide for 36 cancers in 185 countries. CA Cancer J Clin. 2018; 68:394424. https://doi.org/10.3322/caac.21492. PMID:30207593

2. Siegel RL, Miller KD, Jemal A. Cancer statistics, 2020. CA Cancer J Clin. 2020; 70:7-30. https://doi.org/10.3322/ caac. 21590 . PMID:31912902

3. Van Cutsem E, Sagaert X, Topal B, Haustermans K, Prenen H. Gastric cancer. Lancet. 2016; 388:2654-64. https://doi. org/10.1016/S0140-6736(16)30354-3. PMID:27156933

4. Huarte M. The emerging role of lncRNAs in cancer. Nat Med. 2015; 21:1253-61. https://doi.org/10.1038/nm.3981. PMID:26540387

5. Ghasemi T, Khalaj-Kondori M, Hosseinpour Feizi MA, Asadi P. Aberrant expression of lncRNAs SNHG6, TRPM2AS1, MIR4435-2HG, and hypomethylation of TRPM2-AS1 promoter in colorectal cancer. Cell Biol Int. 2021; 45:246478. https://doi.org/10.1002/cbin.11692. PMID:34431156

6. Li J, Xu Q, Wang W, Sun S. MIR100HG: a credible prognostic biomarker and an oncogenic lncRNA in gastric cancer. Biosci Rep. 2019; 39:BSR20190171. https://doi. org/10.1042/BSR20190171. PMID:30886062

7. Li L, Zhang L, Zhang Y, Zhou F. Increased expression of LncRNA BANCR is associated with clinical progression and poor prognosis in gastric cancer. Biomed Pharmacother. 2015; 72:109-12. https://doi.org/10.1016/j. biopha.2015.04.007. PMID:26054683

8. Li H, Yu B, Li J, Su L, Yan M, Zhu Z, Liu B. Overexpression of lncRNA H19 enhances carcinogenesis and metastasis of gastric cancer. Oncotarget. 2014; 5:2318-29. https://doi. org/10.18632/oncotarget.1913. PMID:24810858

9. Yao XM, Tang JH, Zhu H, Jing Y. High expression of LncRNA CASC15 is a risk factor for gastric cancer prognosis and promote the proliferation of gastric cancer. Eur Rev Med Pharmacol Sci. 2017; 21:5661-67. https://doi. org/10.26355/eurrev_201712 14010. PMID:29272000

10. Wei GH, Wang X. IncRNA MEG3 inhibit proliferation and metastasis of gastric cancer via p53 signaling pathway. Eur Rev Med Pharmacol Sci. 2017; 21:3850-56. PMID:28975980

11. Endo H, Shiroki T, Nakagawa T, Yokoyama M, Tamai K, Yamanami H, Fujiya T, Sato I, Yamaguchi K, Tanaka N, Iijima K, Shimosegawa T, Sugamura K, Satoh K. Enhanced expression of long non-coding RNA HOTAIR is associated with the development of gastric cancer. PLoS One. 2013; 8:e77070. https://doi.org/10.1371/journal.pone.0077070. PMID:24130837

12. Benetatos L, Vartholomatos G, Hatzimichael E. MEG3 imprinted gene contribution in tumorigenesis. Int J Cancer. 2011; 129:773-79. https://doi.org/10.1002/ijc.26052. PMID:21400503
13. Sun M, Xia R, Jin F, Xu T, Liu Z, De W, Liu X. Downregulated long noncoding RNA MEG3 is associated with poor prognosis and promotes cell proliferation in gastric cancer. Tumour Biol. 2014; 35:1065-73. https://doi. org/10.1007/s13277-013-1142-z. PMID:24006224

14. Ding L, Tian $\mathrm{Y}$, Wang L, Bi M, Teng D, Hong S. Hypermethylated long noncoding RNA MEG3 promotes the progression of gastric cancer. Aging (Albany NY). 2019; 11:8139-55. https://doi.org/10.18632/aging.102309. PMID:31584879

15. Peng W, Si S, Zhang Q, Li C, Zhao F, Wang F, Yu J, Ma R. Long non-coding RNA MEG3 functions as a competing endogenous RNA to regulate gastric cancer progression. J Exp Clin Cancer Res. 2015; 34:79. https://doi.org/10.1186/ s13046-015-0197-7. PMID:26253106

16. Xu G, Meng L, Yuan D, Li K, Zhang Y, Dang C, Zhu K. MEG3/miR-21 axis affects cell mobility by suppressing epithelial-mesenchymal transition in gastric cancer. Oncol Rep. 2018; 40:39-48. https://doi.org/10.3892/or.2018.6424. PMID:29749532

17. Dan J, Wang J, Wang Y, Zhu M, Yang X, Peng Z, Jiang $\mathrm{H}$, Chen L. LncRNA-MEG3 inhibits proliferation and metastasis by regulating miRNA-21 in gastric cancer. Biomed Pharmacother. 2018; 99:931-38. https://doi. org/10.1016/j.biopha.2018.01.164. PMID:29710493

18. Rinn JL, Kertesz M, Wang JK, Squazzo SL, Xu X, Brugmann SA, Goodnough LH, Helms JA, Farnham PJ, Segal E, Chang HY. Functional demarcation of active and silent chromatin domains in human HOX loci by noncoding RNAs. Cell. 2007; 129:1311-23. https://doi.org/10.1016/j. cell.2007.05.022. PMID: 17604720

19. Liu YW, Sun M, Xia R, Zhang EB, Liu XH, Zhang ZH, Xu TP, De W, Liu BR, Wang ZX. LincHOTAIR epigenetically silences miR34a by binding to PRC2 to promote the epithelial-to-mesenchymal transition in human gastric cancer. Cell Death Dis. 2015; 6:e1802. https://doi. org/10.1038/cddis.2015.150. PMID:26136075

20. Liu XH, Sun M, Nie FQ, Ge YB, Zhang EB, Yin DD, Kong R, Xia R, Lu KH, Li JH, De W, Wang KM, Wang ZX. Lnc RNA HOTAIR functions as a competing endogenous RNA to regulate HER2 expression by sponging miR-331$3 p$ in gastric cancer. Mol Cancer. 2014; 13:92. https://doi. org/10.1186/1476-4598-13-92. PMID:24775712

21. Dong X, He X, Guan A, Huang W, Jia H, Huang Y, Chen S, Zhang Z, Gao J, Wang H. Long non-coding RNA Hotair promotes gastric cancer progression via miR-217-GPC5 axis. Life Sci. 2019; 217:271-82. https://doi.org/10.1016/j. 1fs.2018.12.024. PMID:30557546

22. Xiao J, Lai H, Wei SH, Ye ZS, Gong FS, Chen LC. lncRNA HOTAIR promotes gastric cancer proliferation and metastasis via targeting miR-126 to active CXCR4 and RhoA signaling pathway. Cancer Med. 2019; 8:6768-79. https://doi.org/10.1002/cam4.1302. PMID:31517442

23. Guo Q, Qian Z, Yan D, Li L, Huang L. LncRNA-MEG3 inhibits cell proliferation of endometrial carcinoma by 
repressing Notch signaling. Biomed Pharmacother. 2016; 82:589-94. https://doi.org/10.1016/j.biopha.2016.02.049. PMID:27470401

24. Khajehdehi M, Khalaj-Kondori M, Ghasemi T, Jahanghiri B, Damaghi M. Long Noncoding RNAs in Gastrointestinal Cancer: Tumor Suppression Versus Tumor Promotion. Dig Dis Sci. 2021; 66:381-97. https://doi.org/10.1007/s10620020-06200-x. PMID:32185664

25. Sun KX, Wu DD, Chen S, Zhao Y, Zong ZH. LncRNA MEG3 inhibit endometrial carcinoma tumorigenesis and progression through PI3K pathway. Apoptosis. 2017; 22:1543-52. https://doi.org/10.1007/s10495-017-1426-7. PMID:29094270

26. Orlando V. Polycomb, epigenomes, and control of cell identity. Cell. 2003; 112:599-606. https://doi.org/10.1016/ s0092-8674(03)00157-0. PMID:12628181

27. Mohammad HP, Cai Y, McGarvey KM, Easwaran H, Van Neste L, Ohm JE, O'Hagan HM, Baylin SB. Polycomb CBX7 promotes initiation of heritable repression of genes frequently silenced with cancer-specific DNA hypermethylation. Cancer Res. 2009; 69:6322-30. https://doi.org/10.1158/0008-5472.CAN-09-0065. PMID:19602592

28. Sparmann A, van Lohuizen M. Polycomb silencers control cell fate, development and cancer. Nat Rev Cancer. 2006; 6:846-56. https://doi.org/10.1038/nrc1991. PMID:17060944

29. Liu Y, Wang B, Liu X, Lu L, Luo F, Lu X, Shi L, Xu W, Liu Q. Epigenetic silencing of p21 by long non-coding RNA HOTAIR is involved in the cell cycle disorder induced by cigarette smoke extract. Toxicol Lett. 2016; 240:60-67. https://doi.org/10.1016/j.toxlet.2015.10.016. PMID:26506537

30. Liu FT, Qiu C, Luo HL, Zhang Y, Xia GF, Hao TF, Zhu PQ. The association of HOTAIR expression with clinicopathological features and prognosis in gastric cancer patients. Panminerva Med. 2016; 58:167-74. PMID:26964077
31. Seo SI, Yoon JH, Byun HJ, Lee SK. HOTAIR Induces Methylation of PCDH10, a Tumor Suppressor Gene, by Regulating DNMT1 and Sponging with miR-148b in Gastric Adenocarcinoma. Yonsei Med J. 2021; 62:118-28. $\quad$ https://doi.org/10.3349/ymj.2021.62.2.118. PMID:33527791

32. Zhou X, Ji G, Ke X, Gu H, Jin W, Zhang G. MiR-141 Inhibits Gastric Cancer Proliferation by Interacting with Long Noncoding RNA MEG3 and Down-Regulating E2F3 Expression. Dig Dis Sci. 2015; 60:3271-82. https://doi. org/10.1007/s10620-015-3782-x. PMID:26233544

33. Petkevičius V, Steponaitienè R, Thon C, Skiecevičienè J, Malfertheiner P, Kupčinskas J, Link A. Prognostic role of long non- coding RNA HOTAIR expression in gastric cancer and association with preneoplastic conditions and H. pylori. Helicobacter: EHMSG - XXXIInd International Workshop on Helicobacter \& Microbiota in Inflammation \& Cancer: Innsbruck, Austria, September 5-7, 2019/European Helicobacter and Microbiota Study Group. Oxford, England: John Wiley \& Sons Ltd; 2019. p. 100. https://hdl. handle.net/20.500.12512/22350.

34. Ghasemi T, Khalaj-Kondori M, Hosseinpour Feizi MA, Asadi P. IncRNA-miRNA-mRNA interaction network for colorectal cancer; An in silico analysis. Comput Biol Chem. 2020; 89:107370. https://doi.org/10.1016/j. compbiolchem.2020.107370. PMID:32932199

35. Bian EB, Wang YY, Yang Y, Wu BM, Xu T, Meng XM, Huang C, Zhang L, Lv XW, Xiong ZG, Li J. Hotair facilitates hepatic stellate cells activation and fibrogenesis in the liver. Biochim Biophys Acta Mol Basis Dis. 2017; 1863:674-86. https://doi.org/10.1016/j.bbadis.2016.12.009. PMID:27979710 